\title{
Study on Water Resistance of Polydopamine Treatment Wood Flour/Polypropylene Composites
}

\author{
Do Khoa Thi Lanhi* ${ }^{*}$, Tran Duc Thien² \\ ${ }^{1}$ Department of Polymer Science and Materials, Sichuan University, Chengdu, China \\ ${ }^{2}$ Vietnam National University of Forestry, Hanoi, Vietnam \\ Email: *khoalanh2009@gmail.com
}

Received 18 April 2016; accepted 23 May 2016; published 26 May 2016

Copyright (C) 2016 by authors and Scientific Research Publishing Inc.

This work is licensed under the Creative Commons Attribution International License (CC BY).

http://creativecommons.org/licenses/by/4.0/

c) (i) Open Access

\section{Abstract}

This paper aims to investigate the water absorption of wood flour/polypropylene composites and its effects on dimensional stability and crystallization properties. Wood-plastic composites (WPCs) makes using polydopamine modified wood flour (WF-D), virgin polypropylene, maleic anhydridegrafted polypropylene (MA) and antioxidant, by using hot-pressing moulding. Water absorption (WA), thickness swelling (TS) and failure of flexural properties of the composites have studied for a range of immersion times. It is found that the WA and TS have increased with WF content and immersion time. The water absorption and thickness swelling of WPCs are $0.85 \%$ and $0.99 \%$, respectively, after 8 days immersion. With the prolonging of immersion time, the impact strength, flexural strength and flexural modulus of WPCs increase first and then decrease. The impact strength decreases from $3.32 \mathrm{~kJ} / \mathrm{m}^{2}$ to $2.94 \mathrm{~kJ} / \mathrm{m}^{2}$, the retention rate is $88.55 \%$; the flexural strength and flexural modulus by $68.58 \mathrm{Mpa}$ and $3.92 \mathrm{Gpa}$, respectively. WPCs crystallization and thermal properties decrease slightly. Microstructures of the composites are examined to understand the mechanisms for the wood-plastic interaction which affects the water absorption and thickness swelling. Our work demonstrates that using polydopamine treatment wood flour for preparing WPCs can be an efficient way to improve the water resistance of WPCs.

\section{Keywords}

Wood Flour, Water Absorption, Polypropylene, Wood-Plastic Composites, Polydopamine, Thickness Swelling

\footnotetext{
${ }^{*}$ Corresponding author.
}

How to cite this paper: Lanh, D.K.T. and Thien, T.D. (2016) Study on Water Resistance of Polydopamine Treatment Wood Flour/Polypropylene Composites. Journal of Materials Science and Chemical Engineering, 4, 7-15. 


\section{Introduction}

In recent years, the applications of wood plastic composites have attracted widespread attention such as in the field of construction, automotive and inner-outer room. Compared with the traditional synthetic fibers, wood flour (WF) has low density, non-abrasive nature, low energy consumption, renewable and biodegradable. In addition, they have high specific strength and modulus, low temperature resistance and corrosion resistance and other excellent characteristics [1]-[5]. It is an ideal reinforcing material in wood plastic composites. But because wood flour contains strong water absorption of the composition, which riches hydroxyl, hydrophilic strong. The surrounding environment will be more sensitive for the use of material and preparation of composites. The infiltration of water will destroy the interface between wood powder and resin, which leads to the change of the mechanical properties of WPCs and limit their end-use applications. At present, it is an important application field of WPCs to substitute wood for outdoor building materials and decorative materials. Therefore, the main requirements of WPCs are low water absorption. Otherwise, it will cause a series of problems in the outdoor environment such as deformation or warping, reduction in mechanical strength, reduction in fungal decay resistance, shortening in the material lifetime [6]. Therefore, to study the water absorption of WPCs and its influence it is very important [7].

Polydopamine (PDA) is recently found to be adhesive to universal materials, including metal, ceramics, carbon nanotubes, graphene and polymers [8]. It is also reported that dopamine can be a green and novel surface modifier for natural fiber and can be an efficient way for the interfacial enhancement between matrix and fillers [9].

In this research, the surface modification of wood flour is carried out by polydopamine. PP/WF wood plastic composites are prepared, then it is studied by comparing the change of properties before and after water absorption.

\section{Experimental}

\subsection{Materials}

Polypropylene powder (PP), grade 045, is purchased from Sichuan ShengMa Chemical Industry Stock Co., Ldt, China. Wood flour (WF), particle size of $74 \mu \mathrm{m}$, is provided by Guangdong Jiangmen City Xinhui District Shuangshui Town MuJiang Weihua spice factory, China. Maleic anhydride grafted polypropylene (MAH-g-PP): E-43 Epolene, is purchased from West Lake chemical company, Usa. Dopamine (DA) hydrochloride (99\%) is purchased from J\&K Scientific Ltd. Tris-HCl is purchased from Chengdu Best Reagent Co., Ltd, China. Hydrochloric acid is purchased from Tianjin Bodi Chemical Reagent Co., Ltd, China. Antioxidant, 1010, commercially available.

\subsection{The Treatment of Wood Flour Using PDA}

Firstly, dopamine hydrochloride added to Tris-HCl buffer $(\mathrm{PH}=8.5)$ prepare dopamine solution $(1 \mathrm{mg} / \mathrm{ml})$, and then take a certain amount of WF into the dopamine solution and the solutions were further placed into Heat collection constant temperature type magnetic agitator DF-101S and stirred (stirring speed is about $600 \mathrm{rpm}$ ) for 24 hours at room temperature. The color of the solution has changed from colorless to dark brown after selfpolymerization of dopamine. Followed by suction filtration modified WF rinsed with large quantity distilled water to remove the PDA which was not coated on the wood flour and dry in vacuum oven at $60^{\circ} \mathrm{C}$ for $48 \mathrm{~h}$.

\subsection{Preparation of PP/WF Composites}

Firstly, the weight fraction of WF is $10 \mathrm{wt} \%, 20 \mathrm{wt} \%, 30 \mathrm{wt} \%, 40 \mathrm{wt} \%, 50 \mathrm{wt} \%$, respectively, PP and MAH-g$\mathrm{PP}(\mathrm{PP} / \mathrm{MAH}=80 / 20)$ are added to a high-speed mixer mixing for $5 \mathrm{~min}$. Secondly, the mixture put into torque rheometer mixer that melt the mixture in 5 min (mixing temperature is $180^{\circ} \mathrm{C}$, mixing speed is $60 \mathrm{rpm}$ ) and finally prepare PP/WF composites. Samples for chemical properties test and water absorption test were molded into Micro injection molding under pressure 800 bar, mold temperature $50^{\circ} \mathrm{C}$, and the holding time is $30 \mathrm{~s}$.

\subsection{Performance Testing and Characterization}

Flexural strength tests is carried out according to GB/T 9341-2000 specification, specimens $(4 \mathrm{~mm} \times 10 \mathrm{~mm} \times$ 
$80 \mathrm{~mm}$ ), span $64 \mathrm{~mm}$. According to GB/T 1040.2 - 2006 standard test tensile strength, test sample is dumbbell type. According to GB/T $1043-1993$ standard test impact strength, specimens $(4 \mathrm{~mm} \times 10 \mathrm{~mm} \times 80 \mathrm{~mm})$. The thermal stability was studied with Thermal Gravimetric Analysis (TGA, TA instrument, Q500, USA). The temperature increases from $30^{\circ} \mathrm{C}$ to $600^{\circ} \mathrm{C}$ at a heating rate of $10^{\circ} \mathrm{C} / \mathrm{min}$ in air atmosphere; the melting and crystallization are study with Differential Scanning Calorimeter (Perkin-Elmer, pyris-1 DSC). Under the protection of nitrogen from the room temperature to $5^{\circ} \mathrm{C} / \mathrm{min}$ up to $200^{\circ} \mathrm{C}$, holding $5 \mathrm{~min}$, and then to $5^{\circ} \mathrm{C} / \mathrm{min}$ down to $80^{\circ} \mathrm{C}$, record their melting behaviors; For scanning electronic microscopy (SEM) investigation, the impact specimen cross section was put into Quanta 250 observation.

Determination of water absorption: specimens of wood plastic composite are numbered, weighing and placed in constant temperature water flume $\left(23^{\circ} \mathrm{C}\right)$ for different time. After a certain period of time, immersion specimens are removed from the water, and thoroughly dry with tissue papers, then immediately measure the weight and the thickness. The weight and thickness of specimens are measured to a precision of $0.0001 \mathrm{~g}$ and $0.001 \mathrm{~mm}$, respectively. The percentage of water absorption (MC) can be calculated using Equation (1):

$$
M C=\frac{m-m_{0}}{m_{0}} \times 100 \%
$$

Here $m_{0}$ quality of the specimen before immersion (g); $m$ the quality of specimen after immersion (g).

The percentage of thickness swelling (TS) was calculated using Equation (2):

$$
T S=\frac{t-t_{0}}{t_{0}} \times 100 \%
$$

Here $t_{0}$ thickness of specimen before immersion (mm); $t$ thickness of specimen before immersion (mm).

\section{Results and Discussion}

\subsection{Effect of Immersion Time on the Properties and Water Absorption of Wood Plastic Composites}

The short-term water absorption of the PP/WF composites was monitored by full water immersion for 8 days as shown in Figure 1.

Composites made from polypropylene with $50 \mathrm{wt} \% \mathrm{WF}$ absorbed water, absorption water ratios is $0.85 \%$ (relative to solids by weight) and thickness swelling ratios is $0.99 \%$, respectively, after 8 days. Figure 1 shows that although the wood flour content is very high (WF is $50 \mathrm{wt} \%$ ), but the WPCs water absorption is low ( $<1 \%)$. With the increasing of immersion time, the water absorption rate of WPCs is increased gradually, but the increasing rate is slow. The water absorption rates of composites are still not reach equilibrium after 8 days immersion. Because of the main component of wood flour is cellulose, which contains a large number of hydrophilic hydroxyl. At the same, shows the porous structure and a large number of capillary that the surface tension can easily absorb moisture. On the other hand, due to cellulose absorb moisture it leads to the expansion of the volume, the thickness of specimens that will be correspondingly larger. The water absorption and thickness of

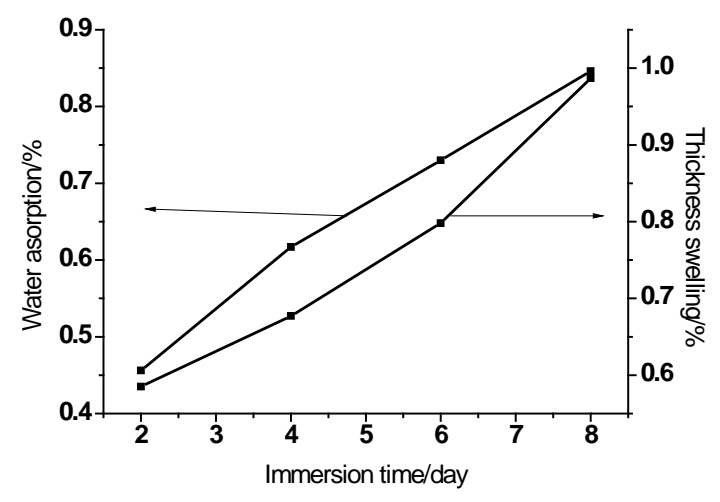

Figure 1. Effect of immersion time on WPC of water absorption and thickness swelling. 
WPCs expansion rate has been increasing. But this increase relatively slows. General particleboard materials in $24 \mathrm{~h}$ after immersion thickness swelling rate reached 10\% [10]. Thus it can be see this wood plastic composite of anti swelling performance is good.

Although, the wood flour content is high, but water absorption and thickness swelling of WPCs were relatively low. There are two possible reasons: one is this may be due to soaking time is not long enough, the amount of water molecules not enough to make structural material damage. The second is because wood flour has treated with polydopamine, while the surface is coated with a layer of strong dopamine. Moreover, wood flour is again coated with plastic matrix, that enhances the bonding strength between the plastic and wood flour. At the same, the composite system also has a certain amount of MA, so the compatibility is more improved.

The flexural properties are important for decision-making of WPCs applications. The failure of flexural strength and modulus of the composites, with WF content is $50 \mathrm{wt} \%$, are shown in Figure 2(a). Figure 2(b) a curve shows the impact strength of WPCs after immersion. From Figure 2(a), Figure 2(b) we can obviously see it first increase and then decrease. This is because the water absorption process further eliminates the residual stress inside the material that leads to reduce the brittleness and increase the toughness of the material. When water molecules infiltrate into the composites, the part of the wood fibers gradually expanded again, and the molecular structure of cellulose destroy, while the bonding strength between PP and wood flour damage which lead to flexural strength, flexural modulus and impact of the strength decrease. After 8 days immersion, the impact of strength decrease from $3.32 \mathrm{~kJ} / \mathrm{m}^{2}$ to $2.94 \mathrm{~kJ} / \mathrm{m}^{2}$ and the retention rate is $88.6 \%$; the flexural strength and modulus is $68.58 \mathrm{Mpa}$ and $3.92 \mathrm{Gpa}$ higher WPCs after 2 days immersion, respectively. This can be explained by better interfacial adhesion between the fibers and the matrix allowing an improvement of stress transfer from the PP matrix to wood flour.

\subsection{Effect of Immersion and Wood Flour Content on the Mechanical Behavior of Wood Plastic Composites}

Water absorption and thickness swelling of WPCs are prepared from different content of wood flour under polydopamine treatment (WF-D) and polypropylene that are shown in Figure 3. Generally, the water absorption and thickness swelling increased with wood flour content because of the main component of wood flour is cellulose, which contains a large number of hydrophilic hydroxyl groups. Hence, an increase of free $\mathrm{OH}$ groups with wood cellulose content. These free $\mathrm{OH}$ groups interact with polar water molecules, leading to the weight gain of the composites. During immersion the wood flour absorbs a significant quantity of water, while the plastics absorbed very little. At the same time, it presents a porous structure that contains a large number of capillary. The surface tension is easy to absorb the moisture, the weight of the composite increases, and finally water absorption increase [11].

One other hand, due to the cellulose absorbs moisture the thickness of the specimen will be correspondingly larger. With increasing the content of wood flour the thickness of the sample increases.

The Figure 4(a), Figure 4(b) shows that the flexural strength decreases from 67.96 to 64.21 Mpa by 5.52\% and respectively flexural modulus decreases from 3.78 to 3.6 Gpa by $4.76 \%$. Figure 4(c) shows the influence of

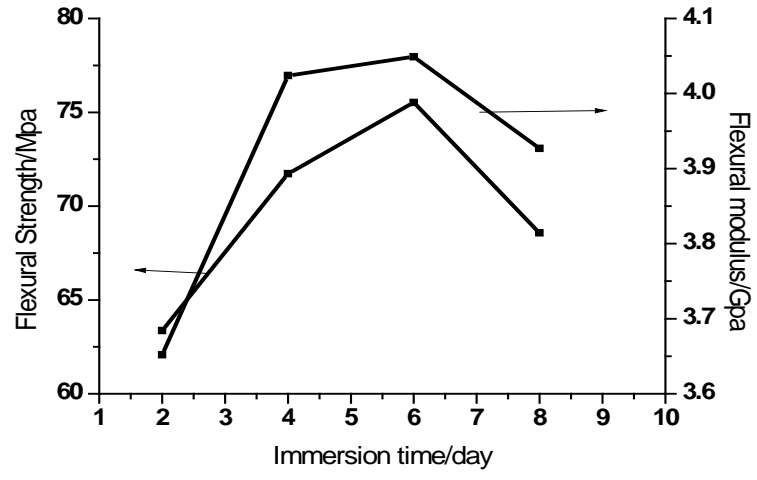

(a)

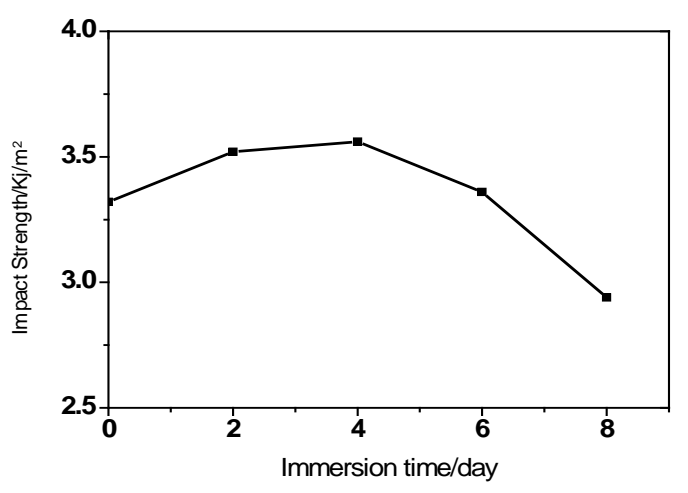

(b)

Figure 2. Effect of immersion time on WPCs properties. 


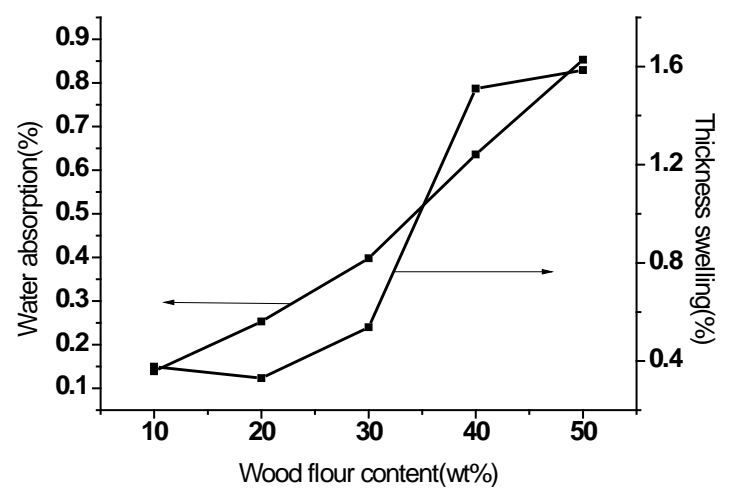

Figure 3. Effect of wood flour content on wood plastic composites of water absorption and thickness swelling.



(a)

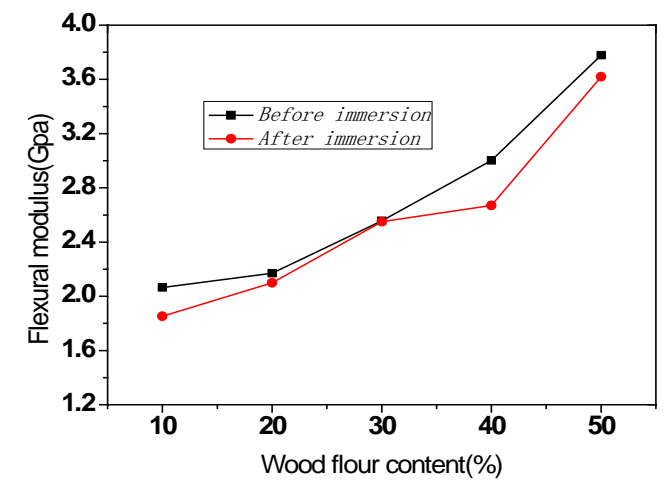

(b)

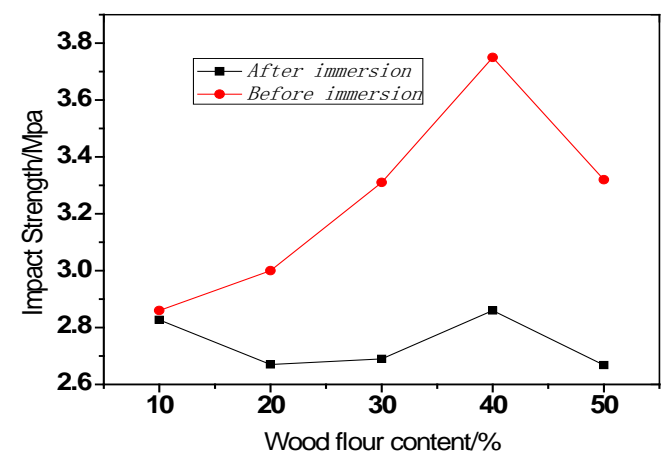

(c)

Figure 4. Effect of wood flour content on wood plastic composites properties.

wood flour content on the impact strength of WPCs after absorbing in the water. The figure also shows that after 8 days immersion, wood flour is respectively $10 \mathrm{wt} \%, 20 \mathrm{wt} \%, 30 \mathrm{wt} \%, 40 \mathrm{wt} \%, 50 \mathrm{wt} \%$ of WPCs, the change of impact strength decreases by $1.2 \%, 13 \%, 18.74 \%, 23.74 \%, 20 \%$ compared with WPCs before immersion. The main reason for hydroxyl increase is due to increase of the content of wood flour, PP content is relatively low. The wood flour is difficult to disperse in PP matrix. The voids and cracks of WPCs increase, when more water molecules absorb which infiltrate composite material. The bonding interface between PP and wood flour is seriously damage, reduced the properties of WPCs [12].

\subsection{Crystallization Properties of Wood Plastic Composites before and after Immersion}

Figure 5 shows the DSC curves which explain the 8 days immersion of WPCs with WF different content (20 


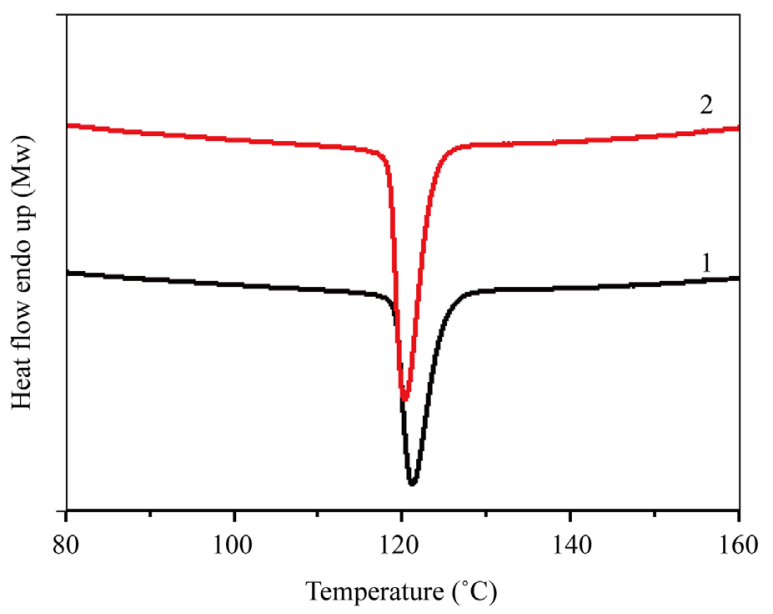

(a)

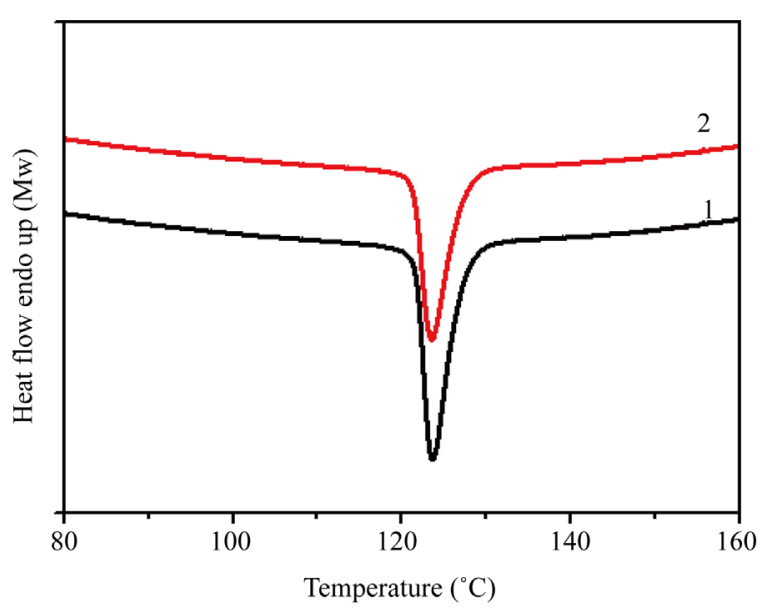

(b)

Figure 5. Non isothermal crystallization curves of wood plastic composites. (a) PP/MA/20WF-D: 1-Before immersion; 2-After immersion; (b) PP/MA/50WF-D: 1-Before immersion, 2-After immersion.

wt\%, 50 wt\%). From the Figure 6 we can see the melting temperature, crystallization temperature and degree of supercooling slightly decrease after immersion. However, the reduction of the value is low. It shows that, when the water has penetrated into the voids and the gully of the material system, the immersion time is short so water penetration is less, the interface of the composite is damaged, but the degree of damage is not serious. The decrease in mechanical properties of WPCs is not very clear. Specific data is shown in Table 1.

\subsection{Thermal Stability of Wood Plastic Composites before and after Immersion}

Figure 6 shows TGA curves of WPCs with WF content by $20 \mathrm{wt} \%$ and $50 \mathrm{wt} \%$ before and after 8 days immersion. Figure 6 shows, the maximum thermal decomposition temperature and residual amount of WPCs after immersion is slightly lower than without soaking water, but not obvious. This because many water molecules enters into the WPCs of the composite material after immersion that reduce interface bonding force between WF and PP. Therefore, low energy is needed to destroy the interface force. The data is shown in Table 2.

\subsection{Microstructure of Wood Plastic Composites before and after Immersion}

In order to have a more in-depth understanding of water absorption of WPCs deformation mechanism. The cross sections of the specimen were analyzed by scanning electron microscopy (Figure 7).

From Figures 7(a)-(d) we can see the wood flour surface of impact section of wood plastic composite materials after immersion. It shows that the surface is attached to a large number of polypropylene resins. The interface of WF and PP is closely bonded. It shows that the bond strength between WF and PP is good. While the Figures 7(e)-(h) obviously seen that, the interface crack is more than the WPCs after immersion. There are many gaps and micro porous in the WPCs section. This shows that the interfacial compatibility of WF and PP has a certain degree of variation in WPCs after immersion. The reason is that the mechanical strength of WPCs decreases after immersion. Wood plastic composites mainly fill with wood flour. Wood flour will be absorbent, and expand after the immersion of WPCs. As a results the stress are produced on the plastic matrix which are coated with wood powder was produced this stress also produce small cracks. Then the interface between wood and plastic is damaged. Finally it affects its mechanical properties.

By Figure 8 we can see wood flour content is $50 \mathrm{wt} \%$ of the wood plastic composite after 8 days immersion, its impact fracture shows destruction severely. When wood flour content is $20 \mathrm{wt} \%$ then impact fracture shows destruction slightly. If the wood flour content is $50 \mathrm{wt} \%$ then the wood flour and PP interface has more gullies, porosity. The reason is that water molecules penetrate into the micro pore and gullies of PP that form a new micro pore and gully. When the wood flour content is higher, water molecules more easily penetrate into the WF and PP interface through the capillary action along the fiber direction then the gully and micro porous more appear that lead to the destruction of the interface bond between the PP and WF. Eventually it leads to the decline 


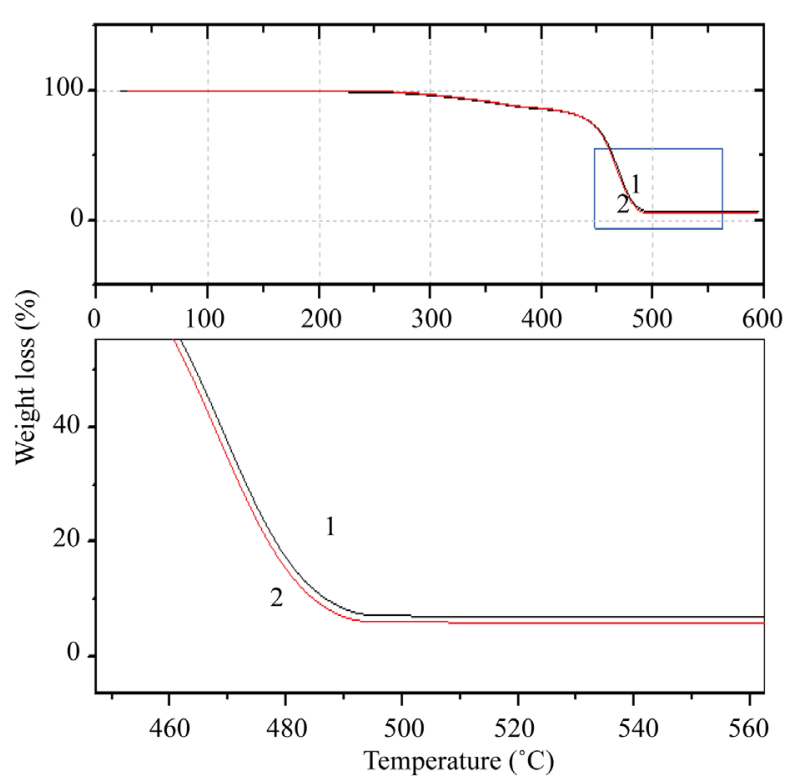

(a)



(b)

Figure 6. TGA curves of PP/WF composites. (a) PP/MAH-g-PP/20WF-D: 1-Before immersion, 2-After immersion; (b) PP/ MAH-g-PP/50WF-D: 1-Before immersion, 2-After immersion.

Table 1. Melting and crystallization properties of the wood-plastic composites.

\begin{tabular}{cccccc}
\hline Sample & WF content (wt \%) & $\begin{array}{c}\text { Melting } \\
\text { temperature }\left({ }^{\circ} \mathrm{C}\right)\end{array}$ & $\begin{array}{c}\text { Crystallization } \\
\text { temperature }\left({ }^{\circ} \mathrm{C}\right)\end{array}$ & $\begin{array}{c}\text { Enthalpy }(\mathrm{J} / \mathrm{g}) \\
\text { Undercooling rate } \\
\Delta \mathrm{T}\left({ }^{\circ} \mathrm{C}\right)\end{array}$ \\
\hline Before immersion & 20 & 163.8 & 121.2 & 50.2 & 42.6 \\
After immersion & 20 & 161.8 & 120.2 & 47.2 & 41.6 \\
Before immersion & 50 & 163.7 & 123.7 & 31 & 40 \\
After immersion & 50 & 161.7 & 123.6 & 27.7 & 38.1 \\
\hline
\end{tabular}

Table 2. TGA data of wood plastic composites after soaking.

\begin{tabular}{ccccccc}
\hline Sample & $\begin{array}{c}\text { Wood flour content } \\
(\mathrm{wt} \%)\end{array}$ & $\mathrm{T}_{5 \%} /{ }^{\circ} \mathrm{C}$ & $\mathrm{T}_{\mathrm{WFmax}} /{ }^{\circ} \mathrm{C}$ & $\mathrm{T}_{\mathrm{PP} \max }{ }^{\circ} \mathrm{C}$ & $\mathrm{T}_{\max } /{ }^{\circ} \mathrm{C}$ & $\mathrm{Y}_{\mathrm{c}} /{ }^{\circ} \mathrm{C}$ \\
\hline Before immersion & 20 & 316.7 & 367.5 & 469.33 & 498 & 6.7 \\
After immersion & 20 & 323.6 & 362.4 & 468.3 & 492.7 & 5.62 \\
Before immersion & 50 & 274.5 & 362.7 & 474.7 & 497 & 15.8 \\
After immersion & 50 & 274.4 & 363.7 & 474.4 & 495.9 & 15.4 \\
\hline
\end{tabular}

Note: initial decomposition temperature $T_{5 \%}\left(5 \%\right.$ weight loss). The maximum decomposition rate of WF and PP is $T_{W F m a x}$ and $T_{P P m a x}$, Maximum decomposition temperature $T_{\max }$, Residue $Y_{C}$.

in properties of the whole wood plastic composites.

\section{Conclusion}

In this work, water absorption (WA) and thickness swelling (TS) of WPCs made using polydopamine modified wood surface are studied. With the water immersion tests, WA and TS increase with wood content and immersion time. After immersion, WPCs have been shown water absorption and thickness swelling low. Even with as high wood content as $50 \mathrm{wt} \%$, the water absorption and thickness swelling of WPCs is still low $(<1 \%)$. The mechanical strength, crystallization and thermal properties of the material slightly decrease, but not too serious. 


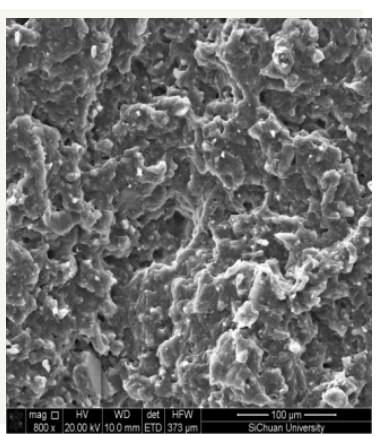

(a)

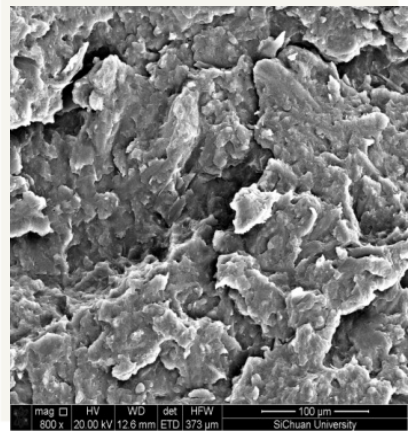

(e)

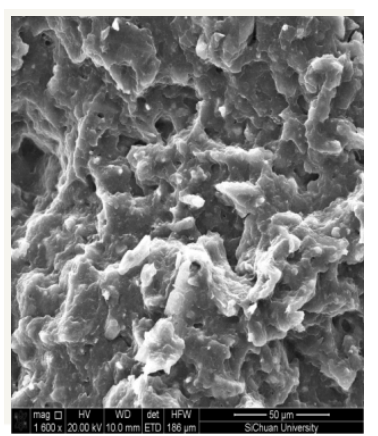

(b)

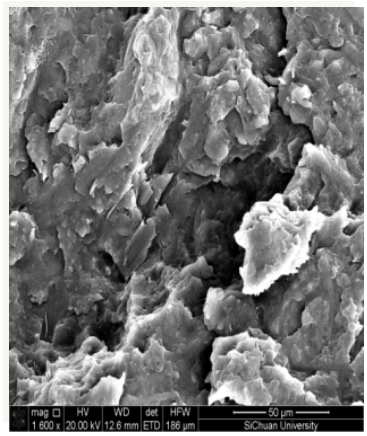

(f)

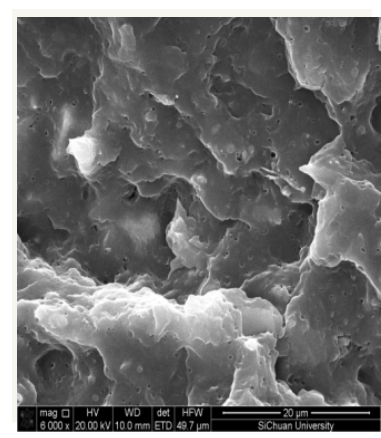

(c)

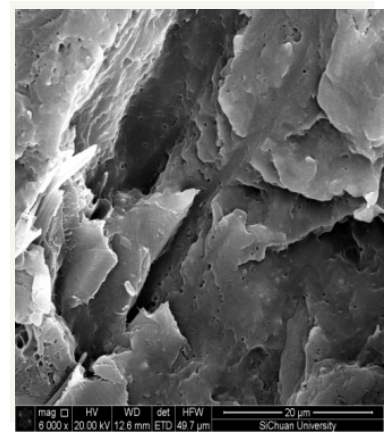

(g)

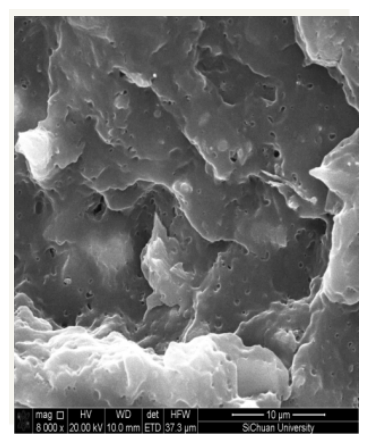

(d)

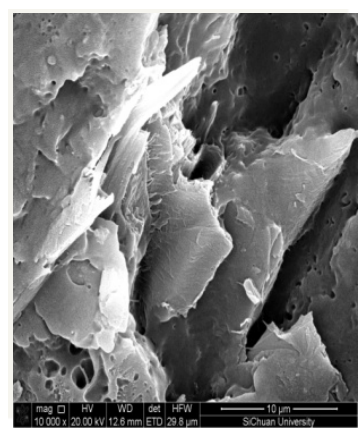

(h)

Figure 7. SEM micrographs for the impact fracture surface of the wood-plastic composites. (a)-(d) Before immersion, (a) (800×); (b) (1600×); (c) (6000×); (d) (10000×); (e)-(h) After immersion, (e) (800×); (f) (1600×); (g) (6000×); (h) (10000).



(a)

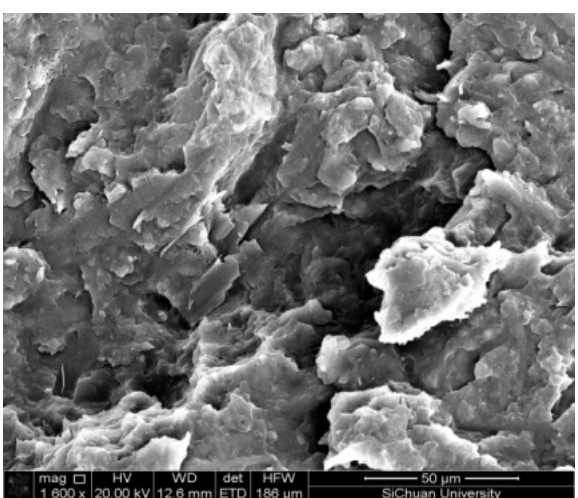

(b)

Figure 8. The fracture surface of wood plastic with wood flour of different content. (a) PP/MA/20WF-D; (b) PP/MA/50WF-D.

It can be said by using a modified wood component in WPCs, it is possible to use a higher wood weight percent in the composites with maintained long-term performance. That is using less thermoplastic matrix, which often is several times more expensive as compared to the wood component. The composites made using polydopamine modified wood material have very low water absorption and thickness swelling thus the products is stable in humid environment. The results and findings of this work provide evidence that the polydopamine modified wood flour can be successfully used to produce stable WPCs suitable for exterior applications in terms of low water absorption and low thickness swelling.

\section{References}

[1] Homkhiew, C. (2013) Optimal Formulation of Recycled Polypropylene/Rubber Wood Flour Composites on Mechani- 
cal and Creep Behaviors. Partial Fulfillment of the Requirements for the Degree of Doctor of Philosophy in Industrial and Systems Engineering Prince of Songkla University.

[2] Wang, Y., Cao, J.Z., Zhu, L.Z., et al. (2012) Interfacial Compatibility of Wood Flour/Polypropylene Composites by Stress Relaxation Method. Journal of Applied Polymer Science, 126, 89-95. http://dx.doi.org/10.1002/app.36682

[3] Livia, D., Karoly, R., Janos, M., et al. (2007) Wood Flour Filled Polypropylene Composites: Interfacial Adhesion and Micromechanical Deformations. Polymer Engineering and Science, 47, 1246-1255.

[4] Ezequiel, P., Lucia, F., Pardo, S.G., et al. (2012) Tensile and Fracture Behaviour of PP/Wood Flour Composites. Composites: Part B, 43, 2795-2800.

[5] Sheng, X.M. and Li, Y.B. (2012) Recent Development of Natural Fiber Reinforced Polymer Composites. New Chemical Materials, 40, 1-3.

[6] Cai, P.X., Lu, Q., Liang, M.J., et al. (2012) Water Absorption and Effect of PP/WPC. China Plastics Industry, 4, 104111.

[7] Liang, M.J., Lu, Q., Cai, P.X. and Cao, Z.H. (2012) Water Absorption of Polyethylene/Wood Flour Composite and Its Effects on Mechanical Properties of the Composite. Plastic, 41, 46-59.

[8] Li, Y.H., Fan, M., Wu, K., et al. (2015) Polydopamine Coating Layer on Graphene for Suppressing Loss Tangent and Enhancing Dielectric Constant of Poly (Vinylidene Fluoride)/Graphene Composites. Composites: Part A, 73, 1-26.

[9] Liu, T., Lu, S.R. and Huang, A.M. (2012) Study on Water Resistance of Polypropylene/Sisal Fiber Wood-Plastic Composites. China Plastics, 26, 76-80.

[10] Sun, Z.Y., Li, D.G., Wu, Z.Y., et al. (2005) Study on the Swell Rate of Wood-Plastic Composites by Soaking in Water. Journal of Fuzhou University (Natural Science), 33, 322-325.

[11] Adhikary, K.B., Pang, S.S. and Staiger, M.P. (2008) Long-Term Moisture Absorption and Thickness Swelling Behaviour of Recycled Thermoplastics Reinforced with Pinus radiata Sawdust. Chemical Engineering Journal, 142, 190198. http://dx.doi.org/10.1016/j.cej.2007.11.024

[12] Tamrakar, S. and Lopez-Anido, R.A. (2011) Water Absorption of Wood Polypropylene Composite Sheet Piles and Its Influence on Mechanical Properties. Construction and Building Materials, 25, 3977-3988. http://dx.doi.org/10.1016/j.conbuildmat.2011.04.031 